\title{
TRAPICHE O INGENIO DE AZÚCAR DE JIMENA DE LA FRONTERA ${ }^{\mathbf{1}}$
}

\author{
TRAPICHE OU INGENIO DE SUCRE DE JIMENA DE LA FRONTERA
}

\author{
ANA MORENO MORENO ${ }^{2}$ \\ Inspectora de Educación
}

Recibido: 01 de octubre de 2019.

Aceptado: 10 de diciembre de 2019.

\begin{abstract}
RESUMEN
La plantación de cañas y la instalación del ingenio para la obtención de azúcar en Jimena de la Frontera se enmarcan dentro de las distintas actividades emprendedoras que inició el VI duque de Medina Sidonia, D. Juan Alonso de Guzmán y Zúñiga. El azúcar de Jimena podía aportar al ducado una nueva fuente de ingresos a través de la venta del producto. Sin embargo, se trató de una empresa arriesgada que estuvo a expensas de las condiciones meteorológicas que fueron las que arruinaron la actividad.Tuvo un importante impacto económico en la zona aunque efímero, y como su vida fue tan breve, no dio tiempo a que tuviera efectos colaterales sobre el paisaje y los recursos.
\end{abstract}

\section{Palabras Clave}

Caña de azúcar; trapiche o ingenio de azúcar; ducado de Medina Sidonia; Jimena de la Frontera; explotación de los recursos naturales.

\section{RESUME}

La plantation de canne à sucre et l'instalation des moulins à sucre à Jimena font partir des différents activités enterprises par le sixième duc de Medina Sidonia, D. Juan Alonso de Guzmán y Zúñiga. Le sucre de Jimena pouvait soporte au duché une nouveau source de reventa grâce à la vente de ces produits. Cependant il s'agissait d'une enterprise risquée qui dépendait des conditions météorologiques, qui furent d'ailleurs à l'origine de la ruine de ce projet d'activité.

Cependant ce projet, bien qu'éphémère, a eu un fort impact économique pour la région mais comme il fut de corte durée, il n'a pas eu le temps d'avoir des conséquences sur le paysage et les ressources.

\section{Mots-CLES}

Canne à sucre; moulin à sucre; duché de Medina Sidonia; Jimena de la Frontera; explotation des ressources naturales.

\footnotetext{
${ }^{1}$ Abreviaturas utilizadas. ADMS $=$ Archivo Ducal de Medina Sidonia; Leg. $=$ Legajo; mrs.= maravedíes.

2 Delegación Territorial de Córdoba. Correo electrónico: ana.moreno.moreno.edu@juntadeandalucia.es. ORCID: https://orcid.org/0000-0002-2727-4613.
} 


\section{INTRODUCCIÓN}

El ingenio de Jimena de la Frontera fue una iniciativa del VI duque de Medina Sidonia, señor de la villa, D. Juan Alonso de Guzmán y Zúñiga (15181558). Ascendió al ducado por decisión de Carlos $\mathrm{V}$, quien determinó que sucediera a su hermano, el V duque, Alonso Pérez de Guzmán y Zúñiga (15131518). Además, le concedió la facultad de que su heredero pudiera utilizar el título de Conde de Niebla.

Mientras estuvo al frente del ducado, amplió el palacio familiar en Sanlúcar de Barrameda y mandó construir el castillo de Zahara, lugar que le sirvió de residencia, factoría y defensa de sus almadrabas, una de las principales fuentes de riqueza de sus dominios. Emprendedor, como los humanistas de su tiempo, trató de introducir el cultivo de la alfalfa en Sanlúcar, el pastel o añil en tierra de Vejer, la seda en Almonte y la caña dulce en Jimena. ${ }^{3}$

En este trabajo nos hemos centrado en la empresa de obtención de azúcar en tierras de la villa de Jimena de la Frontera y para ello hemos utilizado la documentación que se conserva en el Archivo Ducal de Medina Sidonia. Entre ella un expediente al que el archivero de la casa denominó Papeles por donde consta haberse establecido en Jimena por el Sr. Duque D. Juan Alonso un trapiche o ingenio de azúcar en el año de $1546 .{ }^{4}$ Son cartas de pago efectuadas a diferentes personas que se ocuparon de poner en marcha el ingenio. También son significativos los Recados de la cuenta de Francisco Díaz, recaudador de Jimena desde el año 1544 hasta 1551, que ofrecen importante información de todas las labores realizadas tanto en la plantación de las cañas como en el proceso de elaboración del azúcar, y los Asientos y Memoriales del pleito que la Casa Ducal mantuvo en la Real Chacillería de Granada por cinco dehesas del término de Jimena, que incluyen testimonios de la plantación de cañas en una de ellas. ${ }^{5}$

Dentro de las tierras del ducado había que encontrar un lugar que cumpliera con los requisitos necesarios tanto para el cultivo de la caña como para el desarrollo de la industria, y, finalmente, se eligió Jimena de la Frontera. Para estimar si las tierras de su término eran apropiadas para llevar a cabo dicha empresa, se contrató a un maestro de azúcar maderiense.

Además de las condiciones favorables de las tierras, el emplazamiento debía ser adecuado para el aprovisionamiento de materiales y para la distribución de la azúcar elaborada. Jimena podía serlo, pues el estado de Medina Sidonia disponía de sus propios canales para el traslado y distribución de los productos, tanto para los que se llevaban a la villa de Sanlúcar desde las diferentes posesiones ducales, como para los que llegaban a través del mar a Cádiz, donde

\footnotetext{
${ }^{3}$ Álvarez de Toledo, L.I., Alonso Pérez de Guzmán, General de la Invencible, t. 1, Cádiz, 1984, p. 17.

${ }^{4}$ ADMS Leg. 1041, Jimena, 1546, Papeles por donde consta haberse establecido en Jimena por el Sr. Duque D. Juan Alonso un trapiche o ingenio de azúcar en el año de 1546.

${ }^{5}$ ADMS, 2451 Cuentas de los tesoreros Cristóbal Martínez, Rodrigo Morcillo, Alonso Martín Collado, Francisco Díaz y Roque de Soto de Jimena, Gaucín y sus lugares. Años 1529-1569; ADMS, Leg. 1034, Inventario pleito sobre Jimena, 1471-1554; ADMS, Leg. 1038, Jerez, 1574.X.10, Copia autorizada de las Reales Cédulas y diligencias en su virtud hechas por Pedro Beltrán de Guevara para medir y apear las dehesas que en el término de Jimena vendió S.M. a la Casa de Medina Sidonia y posesión que de ellas se la dio por el Ldo. Alonso Carriazo alcalde de la Real Audiencia de Sevilla; Vid. Molina, S. y Moreno, A., «Explotación de los recursos en el entorno natural de Jimena de la Frontera tras la conquista cristiana a finales de la Edad Media», Revista Meridies, 8, Córdoba, 2006, pp. 141-154.
} 
personas de confianza del duque se ocupaban del correspondiente reparto hacia los lugares donde eran necesarios. Concretamente, de Jimena, la casa ducal se aprovisionaba de puercos jabalíes y de frutas, que quedaban almacenadas en origen hasta que eran necesarias, porque en Sanlúcar, «por los aires de la mar», se conservaban muy mal y se dañaban. También se enviaron plantones de nogal y estacas de limones, toronjas y cidros para el jardín del duque. ${ }^{6}$ Desde el mar, pasando por Cádiz, llegaban los productos a Jimena a través de Gibraltar.

\section{EL SEÑORÍO DE JIMENA}

La villa de Jimena está situada en el sector norte del Campo de Gibraltar, al pie de la serranía de Ronda. Esta ubicación fue determinante en los tiempos bajomedievales en los que fue un «poblamiento de frontera» tanto en lo que se refiere a la configuración del poblamiento como en lo relativo al aprovechamiento de los recursos naturales.

El duque de Medina Sidonia la compró, en 1471, al duque de Alburquerque, y ya entrado el siglo XVI, en 1503, después de superado el pleito con los herederos de este por la posesión de la misma, por Privilegio de la reina Isabel la Católica, fue incorporada, con todas sus pertenencias, al mayorazgo de la Casa Ducal. $^{7}$

Debido a la inseguridad fronteriza, el número de pobladores fue escaso hasta 1485, cuando se produjo la conquista de Ronda y la zona se estabilizó. Desde esta fecha, y a lo largo del siglo XVI hubo un espectacular crecimiento. En Jimena se pasó de los 605 vecinos en 1528, a los 1.500 en 1587, superando en 60 vecinos a la población de la capital del ducado, Sanlúcar de Barrameda.

Este aumento de población sostenido debió ejercer una fuerte presión sobre los recursos económicos disponibles, y será pasado el primer tercio del siglo $\mathrm{XVI}$, cuando los vecinos de Jimena comiencen a reclamar como propias las tierras que estaban bajo el poder de los duques, iniciando una serie de pleitos con el fin de intentar corregir esta situación. Precisamente la iniciativa de la caña dulce comenzó en 1538, cuando el duque se encontraba inmerso en un pleito con los vecinos del lugar por la jurisdicción de la villa.

Al ser tierra poco llana, la actividad económica más relevante era la ganadera, sector que estaba controlado por la oligarquía local, la única que podía hacerse con los arrendamientos que se daban en pública subasta. ${ }^{8}$ El principal ganado de las dehesas de Jimena era el vacuno, aunque también pastaban o se «engordaban» otros animales como ovejas, cabras, yeguas y bueyes, los cuales se utilizaban para las labores de labranza. Las bellotas de los alcornoques se usaban para alimentar puercos. La permanencia del ganado dependía de la existencia de abrigo para el invierno y de abrevaderos. Los ríos Guadiaro y Hozgarganta suministraban agua a numerosas dehesas, aunque este último, en algunas zonas, se secaba durante el verano y era necesario hacer pozos en su cauce, de poca profundidad, para sacar el agua.

\footnotetext{
${ }^{6}$ Molina, S. y Moreno, A., «Explotación de los recursos...», pp. 149-151.

${ }^{7}$ Molina, S. y Moreno, A., «Poblamiento y ocupación del territorio en una villa de frontera: Jimena», Actas del III Congreso de Historia de Andalucía, Andalucía medieval, t. 1, Córdoba, 2003, p. 112.

${ }^{8}$ En un Testimonio de la puja y prometido en la dehesa de Diego Díaz de 1541, están recogidos los nombres de las personas que pujaron con especificación del tiempo, el precio y el prometido. ADMS, Leg. 2451, Cuentas de los tesoreros..., Años 1529-1569.
} 
Respecto a la agricultura, el principal cultivo era el trigo. Además, se sembraba cebada, zahína, garbanzos, lino, habas y alverjones. La producción de trigo no era muy grande si la comparamos con otras villas del señorío como Vejer, pero servía para su abastecimiento. La presión demográfica del momento, más determinados intereses sociales, llevaban a tolerar, hasta cierto punto, las sementeras realizadas en tierras de pasto (baldíos, «extremos o cortes» de los ganados). ${ }^{9}$ No fueron muchas las tierras dedicadas a regadío por la dificultad de obtener el agua de los ríos. Las huertas existentes se poblaron de árboles frutales como naranjos y cidros.

El ducado poseía en el término de Jimena cinco dehesas: Diego Díaz, Alcachofal, Santa María, Montenegral y Hoyos de Guadarranque. Entre ellas se eligió la de Diego Díaz para la plantación de las cañas y la instalación del ingenio de azúcar, porque era la única que contaba con agua abundante durante todo el año. Se encontraba a media legua de la villa. Tenía unas 1.120 Ha de tierra rasa, excepto una ladera de monte que lindaba con la sierra de Jimena. Por ella pasaba el río Guadiaro que le servía de lindero, al igual que los baldíos de la villa, heredades de los vecinos y una dehesa boyal llamada la Dehesilla del concejo. ${ }^{10}$

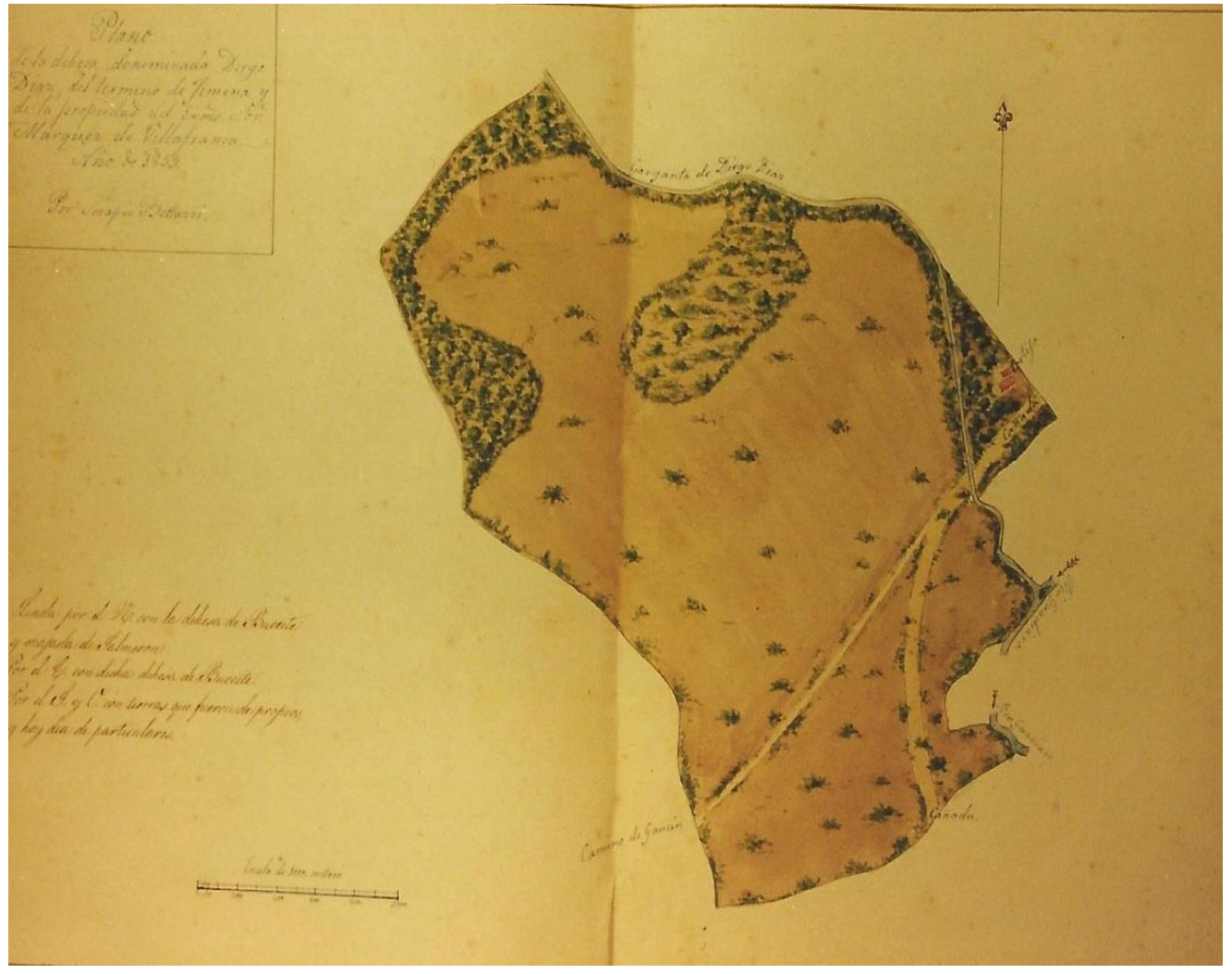

Fig. 1. Plano de la Dehesa de Diego Díaz realizado por Serafín Beltrani para el Marqués de Villafranca en 1853. (ADMS, Leg. 694, Vecindarios y caudales de los pueblos del Estado de Medina Sidona. Año 1778).

\footnotetext{
${ }^{9}$ Ladero Quesada, M.A., «Sector agrario y ordenanzas locales: el ejemplo del ducado de Medina Sidonia y el condado de Niebla», Los señores de Andalucía. Investigaciones sobre nobles y señoríos en los siglos XIII a XV, Universidad de Cádiz, Cádiz, 1998, pp. 255-272.

${ }^{10}$ ADMS, Leg. 1041, Copia de la averiguación que hizo Pedro Beltrán de Guevara del valor de las dehesas del término de Jimena; Leg. 1035, Copia del apeo, medida y amojonamiento de las dehesas del término de Jimena (1572-1574).
} 
Contaba con dos Vegas, la de Corchadillo y la de los Granados y precisamente fue en esta última donde se tomó la decisión de plantar las cañas y edificar el ingenio.

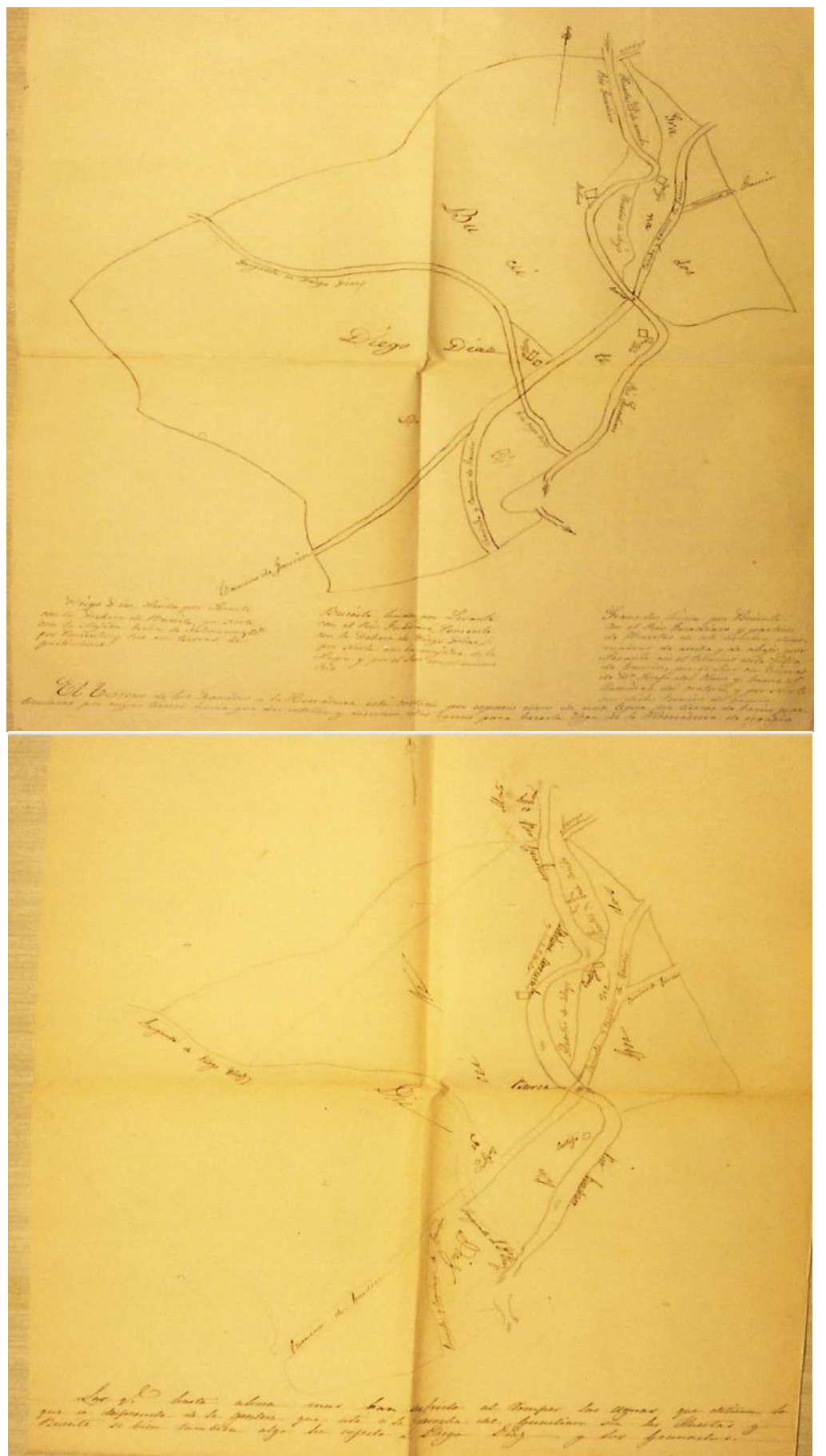

Fig. 2 y 3. Planos de la Dehesa de Diego Díaz, Buceite y La Vega de los Granados, con descripción de sus linderos. (ADMS, Leg. 694, Vecindarios y caudales de los pueblos del Estado de Medina Sidona. Año 1778). 


\section{LA PLANTACIÓN DE LAS CAÑAS}

La caña de azúcar fue un producto medieval que los árabes introdujeron en la Península. Después se asentó en la Macaronesia (Madeira y Canarias) y desde ahí se extendió al Nuevo Mundo. A Marruecos llegó por los genoveses. ${ }^{11}$ Fueron también los árabes los que establecieron los sistemas de producción del azúcar, así como un gran número de combinaciones de las tecnologías ya existentes para que el agua recogida de una forma determinada pudiera ser, sucesivamente, y mediante distintos mecanismos, almacenada, canalizada y elevada. ${ }^{12}$

Los principales centros de plantación de cañas y producción de azúcar en la península, ya desde época andalusí, se encontraban en el bajo Guadalquivir, más al sur de Sevilla, y en el sudeste, en la costa que se extiende desde Málaga hasta Almería. ${ }^{13}$ En el siglo XV, cobran auge otros enclaves como la comarca GandíaOliva, en el reino de Valencia. ${ }^{14}$ Pero la gran expansión azucarera se produjo a partir del siglo XVI, debido, seguramente, a los cambios en la alimentación en las ciudades mientras que en las zonas rurales se mantuvo el uso de la miel, que era mucho más económica. ${ }^{15}$

Los requisitos necesarios para la plantación de las cañas eran suelos arcillosos y calcáreos, fundamentalmente los de aluviones porque la cal tiene un efecto beneficioso en la planta. También temperaturas medias entre 19 y 20 grados centígrados en época primaveral y estival, con suficientes horas de sol y sin heladas, agua para el riego, y, por último, unas vías de acceso a la plantación, a los lugares cercanos y al ingenio.

El almacenamiento de agua era un elemento imprescindible, pues en la Baja Andalucía no coincide la estación de lluvias con la época de crecimiento de la caña -los meses secos del verano- y por ello es necesaria la irrigación, que en esta zona nunca alcanzó mucho desarrollo. ${ }^{16}$ Fueron los moriscos, tras la conquista cristiana, los que llevaron a cabo producciones de este tipo. Como señala Domínguez Ortiz, está demostrado que eran superiores a los cristianos viejos en materia de regadíos ya que se exige una laboriosidad que ellos practicaban en más alto grado que los cristianos. Por este motivo, en el momento de la expulsión, se exceptuaron de la medida a los que se podrían denominar técnicos hidráulicos. ${ }^{17}$

\footnotetext{
${ }^{11}$ Rosenberger, B., «La production de sucre au Maroc au XVI ${ }^{\mathrm{e}}$ siecle. Aspects techniques et sociaux», Agua, trabajo y azúcar, Actas del sexto Seminario Internacional, Granada, 1996, pp. 147-179.

${ }^{12}$ Malpica, A., «Arqueología y azúcar, estudio de un conjunto preindustrial azucarero en el Reino de Granada: La Palma (Motril)», La caña de azúcar en el Mediterráneo, Actas del II seminario Internacional, Granada, 1991, p. 125; Watson, A., «Innovaciones agrícolas en el mundo islámico», La caña de azúcar en el Mediterráneo..., p. 11.

${ }^{13}$ García Sánchez, E., «Caña de azúcar y cultivos asociados en Al-Andalus», Paisajes del azúcar, Granada, 1995, p. 48.

${ }^{14}$ Gisbert, J.A., «En torno a la producción y elaboración de azúcar en las comarcas de la SaforValencia- y la Mariana Alata-Alicante. Siglos XIV-XIX. Arquitectura y la evidencia arqueológica», La caña de azúcar en el Mediterráneo..., pp. 211-265.

15 Bresc, H., «La canne a sucre dans la Sicilia medievale» en La caña de azúcar en el Mediterráneo..., p. 45; Martínez Martínez, M., «Producción de azúcar en Murcia: un proyecto fracasado del siglo XV» 1492: Lo dulce a la conquista de Europa, Granada, 1994, p. 149.

${ }^{16}$ Malpica, A., «Arqueología y azúcar...», pp. 125-126; Malpica, A., «Medio físico y territorio: el ejemplo de la caña de azúcar a finales de la Edad Media», Paisajes del azúcar..., p. 17.

${ }^{17}$ Domínguez Ortiz, A., «Aspectos sociales del cultivo y consumo del azúcar en España», Discurso de Clausura del sexto Seminario Internacional, Agua, trabajo..., p. 330.
} 
En las posesiones del ducado, en tierras de Jimena, el maderiense Juan Myns estudió la viabilidad del proyecto. Estuvo once días inspeccionando la zona, un trabajo por el que se le pagaron, en 1538 , ocho ducados de oro $(3.000 \mathrm{mrs}.){ }^{18}$ Finalmente, se eligió la Vega de los Granados que, como ya se ha señalado, estaba situada en la dehesa de Diego Díaz. El río Guadiaro le servía de lindero con el resto de la dehesa, pero siempre se habían considerado unidas, aunque fue justamente cuando el duque comenzó con este negocio cuando «se desmembró para plantar cañas dulces para hacer almacenero de azúcar». En el otro extremo era frontera con el término de Gaucín.

Para iniciar el proceso se le pidió a Alonso García Navarro, arrendatario de toda la dehesa, que traspasara 12 fanegas de sembradura rata por sueldo de esta Vega, y «en ellas sembraron cañas de azúcar y les acudio mucho y le rogaron que les dejase toda la Vega... y al segundo año la poblaron toda de caña de azúcar y acudio muy bien». ${ }^{19}$

La Vega tenía unas cinco caballerías y media, es decir 230 fanegas de sembradura, pero 10 de ellas eran de un arenal por el que pasaba el río en sus crecidas. ${ }^{20}$ Del total, unas 70 eran de vega, más apropiadas para huerta, aunque no era fácil sacar el agua de riego porque el río era muy caudaloso y profundo, y por ello era necesario hacer norias o aprovechar los calces que se habían hecho para el aprovisionamiento de los molinos. Los dueños de estos no estaban conformes porque limitaba la producción y por ello intentaban evitarlo.

De los dos molinos que había en ella, el del Batán era propiedad del duque, y el de la Jerezana, en 1572, pertenecía a Miguel Sánchez Collado, vecino de Jimena y miembro de la oligarquía local. En los dos andaban dos piedras de moler, desde mayo hasta San Miguel, porque en el invierno la gente prefería acudir a los que estaban más cercanos a la villa. Miguel Sánchez estimaba en un $50 \%$ las pérdidas en los molinos si se aprovechaban las tierras para riego, pues en todo el verano solo podrían utilizar una de las dos piedras para moler. Sin embargo, por los testimonios recogidos en el Memorial no parece, como ocurrió en otras partes, que los vecinos se opusieran a la plantación de las cañas y a la posterior obtención del azúcar. ${ }^{21}$

\footnotetext{
${ }_{18}$ ADMS, 1041, Jimena, 1546 Papeles por donde... Sevilla, 22 de marzo de 1538, Carta de pago.

${ }^{19}$ ADMS, Leg. 1041, Copia de la averiguación..., Jimena, 1572.XI.21.

${ }^{20}$ ADMS, Leg. 1035, Copia del apeo... En el proceso de averiguación del valor de las cinco dehesas, se procedió a la descripción de los linderos y la medición de cada una de ellas. «Después de medida y requerida la cuerda con que se han medido las demás dehesas, se comenzó a medir la Vega de los Granados por Baltasar de Lerma y Antonio de Baro medidores de las demás dehesas yendo por la mojonera adelante guiándolos Francisco Sánchez Churrasco y Martín López. Se comenzó a medir por el mojón que está junto a la Vega del Batán que linda con el río Guadiaro y de allí al mojón que está junto a la Venta de Diego de Arcos, de allí por la mojonera adelante hasta llegar al cerro del Adoratorio, de allí abajo por una linde derecho al río Guadiaro, de allí por el río arriba hasta llegar al dicho mojón del batán».

${ }^{21}$ Malpica, A., «Medio físico y territorio...», pp. 34-35. En Algeciras, en 1516, los vecinos pleitearon con Francisco Piña porque no querían permitirle que plantara cañas de azúcar en el río de la Miel. La iniciativa la había tomado un mercader de Gran Canaria y en ella participaban el Marqués de Tarifa y otros propietarios y hombres de negocios. También los vecinos se negaban a la construcción de los ingenios por la cantidad de leña que consumían.
} 


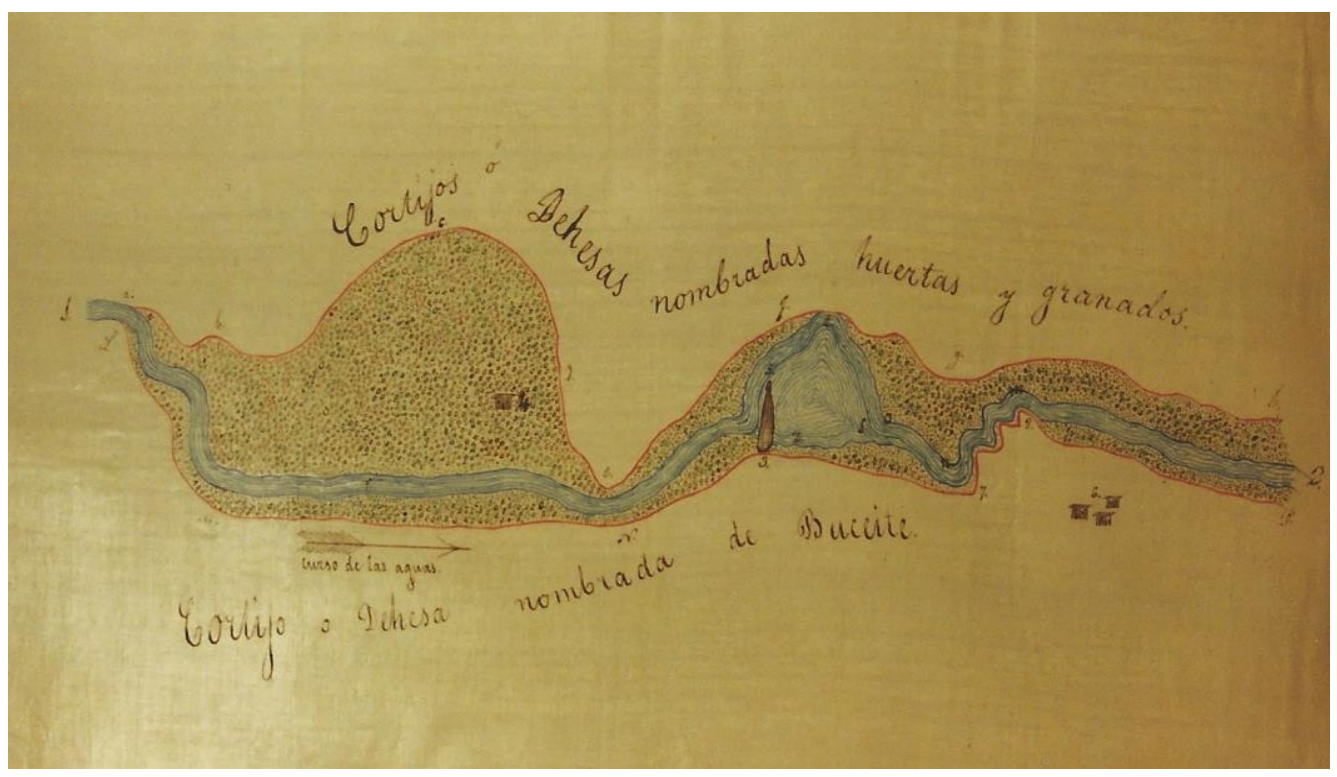

Fig. 4. Curso de las aguas entre las dehesas de Granados y Buceite. (ADMS, Leg. 694, Vecindarios y caudales de los pueblos del Estado de Medina Sidona. Año 1778).

La Vega tenía, además, tres huertas: la Jerezana, de cuya mitad era también propietario Miguel Sánchez Collado, la de Gelo y la de Gaitán, y contaba con una venta llamada de Diego de Arcos que en 1572 estaba despoblada, pero cuando había venteros se vendían y compraban cosas sin pagar alcabala porque estos vecinos eran francos. ${ }^{22}$

Los trabajos para la plantación y cultivo de la caña eran similares en las distintas zonas peninsulares. Destaca especialmente Motril, estudiado de manera amplia por el profesor Malpica. Allí se preparaba la tierra en el mes de enero para poder sembrar la caña de sus raíces a los 20 días del mes de marzo, a distancia de codo y medio una de otra. Después se cubrían de tierra y estiércol con un espesor de tres dedos y comenzaban a regarse al pasar el cuarto día. Cuando los tallos brotaban, se abonaba el terreno con estiércol tras hacer una escarda. La plantación debía ser regada cada semana hasta el mes de octubre, fecha límite para que las cañas no perdieran dulzura. ${ }^{23}$

El testimonio de Tomé Gil, maestro de las cañas dulces, también llamado cañaverero y cañaducero, en 1544, ante el recaudador de Jimena, nos da a conocer todo el proceso, el personal empleado y los salarios que se pagaron en la plantación de las cañas en la Vega de los Granados. Así sabemos que, a comienzos del mes de abril y durante todo el mes, se aró y surcó la tierra donde se iban a plantar las cañas. Para ello se usó el arado de rejas tirado por bueyes. Este trabajo se denominaba en esta tierra «echar huebras».

Las labores de plantación comenzaron el 26 de abril y duraron hasta el 17 de mayo. Se plantaban las cañas y se abrían las zanjas. Durante los meses de junio y julio se procedía a cavar las cañas utilizando azadas y picos, y para el escardado o «rozar la yerva entre las cañas» se usaron «zimbaras» o especie de guadañas.

\footnotetext{
${ }^{22}$ ADMS, Leg. 1038, Jerez, 1574.X.10, Copia autorizada de las Reales Cédulas... .

${ }^{23}$ Malpica, A., «Arqueología y azúcar...», p. 130 y Malpica, A., «Medio físico y territorio...», p. 17.
} 
Otra tarea importante es la referente al riego. En Jimena se comenzaba a regar a principios de mayo y se terminaba en el mes de septiembre. Había que reforzar en el mes de agosto, el periodo más caluroso, para poder garantizar la humedad necesaria para el crecimiento de la planta.

Con el fin de tener agua suficiente, se construyó, utilizando esparto, una acequia para sacar agua del río Guadiaro. Durante todo el tiempo que funcionó el ingenio se realizaron en ella labores de limpieza y mantenimiento. Todavía en 1572 se conservaba, pues los testigos, al hablar de la posibilidad de tener huertas en la Vega de los Granados, decían que se podía utilizar la «acequia vieja que hizo el duque cuando la plantó de cañas dulces [...] por donde se solían regar las dichas cañas dulces».

Cada año se cortaba el cáñamo para conservar su semilla para la siembra del siguiente. Esta tarea implicaba una gran responsabilidad pues había que hacer un corte limpio, con mucho cuidado y precisión, para permitir que la caña volviera a retoñar de nuevo, y sobre todo había que evitar que la planta fuera arrancada. ${ }^{24}$

El maestro de las cañas era el máximo responsable de la salud del cañaveral durante el tiempo por el que era contratado. Por ocuparse de la plantación cobraba un salario mensual y debía permanecer en ella para supervisar el crecimiento de las cañas. En los años 1544 y 1545 el cañaverero fue, como ya se ha dicho, Tomé Gil, a quien se le pagaron mensualmente $1.000 \mathrm{mrs}$. y una fanega de trigo, mientras que en 1546, se dio el puesto de mayordomo de las cañas dulces a Luis Gelo, vecino de Jimena, quien por su trabajo cobró 15.000 mrs. ${ }^{25}$

Los moriscos fueron agentes importantes en la puesta en marcha y desarrollo de este cultivo. La plantación de las cañas dulces en Jimena fue anterior a su expulsión, aunque solo hemos encontrado una alusión a uno de ellos, Alfonso Sánchez, a quien en 1551 se le pagaron 29 mrs. por un día que sirvió en el ingenio. ${ }^{26}$ Según los testimonios de 1572 para la averiguación del valor de las cinco dehesas, fueron los moriscos quienes aprovecharon las vegas para el regadío y plantaron lino. Los arrendatarios de las mismas no pudieron responder a las cuestiones sobre el regadío porque eran los moriscos los que trabajaban en esas tierras de riego y para esas fechas ya habían sido expulsados. Sí recogen que, gracias a unos moriscos vasallos del duque, este, cuando fue despojado de las cinco dehesas, pudo probar que la Vega de los Granados se había deslindado de la dehesa de Diego Díaz cuando se plantaron las cañas y por ello pudo recuperar la posesión de la misma. ${ }^{27}$

Una vez cortadas las cañas en la plantación, debían limpiarse de la punta y de las hojas, las cuales se utilizaban para alimento del ganado. Luego había que atarlas en manojos o haces y colocarlas en un lugar apropiado donde se pudiera entrar con los animales para cargarlas y trasladarlas hasta el ingenio con prontitud, ya que al pasar más de 72 horas sin moler podían perder su riqueza en sacarosa. ${ }^{28}$ Para ello se acordaron con vecinos de la villa que pusieron a disposición sus asnos y caballos. Por el trabajo diario de un asno se pagaban 25 mrs. y un almud de cebada.

\footnotetext{
${ }^{24}$ Lobo Cabrera, M., «Azúcar y trabajo en Canarias», Agua, trabajo..., p. 228.

25 ADMS, Leg. 2451, Cuentas de los tesoreros... Recados de la cuenta de Francisco Díaz recaudador de Jimena del año 1547, Sanlúcar, 1547.V.4.

${ }^{26}$ ADMS, Leg. 2451, Cuentas de los tesoreros..., Recados de la cuenta de Francisco Díaz recaudador de Jimena del año 1551, Jimena, 1551.III.26.

${ }^{27}$ ADMS, Leg. 1041, Copia de la averiguación...; Leg. 1035, Copia del apeo..., Molina, S. y

Moreno, A., «Explotación de los recursos...», p. 149.

${ }^{28}$ Malpica, A., «Medio físico y territorio...», p. 26.
} 


\section{EL INGENIO DE AZÚCAR}

Según el profesor Malpica, las instalaciones para la obtención del azúcar se llaman ingenios cuando son movidas por la fuerza hidráulica y trapiches si lo hacen por tracción animal. El término castellano trapiche procede del catalán trapig, que fue importado de Sicilia. ${ }^{29}$ El expediente del archivo ducal contiene en el título los dos términos, trapiche e ingenio, pero nos consta que en Jimena se utilizó la energía del agua. Por otro lado, en el resto de la documentación se nombra siempre como ingenio $\mathrm{y}$, precisamente se llevó a Jimena, antes de acometer la empresa, a un maestro de hacer ingenios de Madeira, que eran los grandes expertos en la instalación de los ingenios de agua. ${ }^{30}$ Además, ya existían molinos en el río que usaban la fuerza hidráulica.

En España se utilizaron para la fabricación del azúcar técnicas derivadas de otros procesos industriales de mayor antigüedad, en especial de la molienda y prensado de la aceituna. Como fuerza motriz se tomaron los modelos de los molinos harineros de rodezno y las aceñas de rueda vertical. ${ }^{31}$ En sus orígenes, la aceña era una rueda movida por la fuerza humana o animal, pero desde época islámica, el vocablo pasó a designar una rueda hidráulica vertical.

A finales de 1546, se decidió levantar el ingenio de Jimena. En primer lugar, se pidió a Bartolomé Díaz, carpintero de hacer ingenios, y a Alfonso Muñoz, también carpintero, vecino de Sanlúcar, que realizaran el estudio del lugar donde se iba a edificar y que examinaran las maderas. Al último lo acompañó el cañero Juan Hernández con objeto de que informara sobre la instalación de los caños de agua. ${ }^{32}$ El lugar elegido debía tener suficiente agua para el funcionamiento de la maquinaria e importantes cantidades de leña como fuente de energía para las calderas, y debía encontrarse cerca de las zonas de aprovisionamiento. Por otro lado, para garantizar la venta del azúcar era necesario instalar los ingenios o trapiches en zonas cercanas a los núcleos urbanos o bien contar con unas vías seguras de distribución.

El ingenio de Jimena se construyó en la misma Vega de los Granados, junto a la plantación, apartado del núcleo urbano. Estaría al otro lado del río Guadiaro, que servía de lindero con el resto de la dehesa, porque hubo que pagar al arrendador de la renta de la barca de Guadiaro por el trabajo de pasar la gente, acémilas y otras cosas necesarias en el ingenio. ${ }^{33} \mathrm{Al}$ carpintero Bartolomé Díaz, también llamado maestro del ingenio y maestro de la madera del ingenio, se le encargó su obra y se le pidió que se ocupara de las vigas.

Para conseguir la energía hidráulica, había que proceder a la conducción del agua del río, que en este caso era muy caudaloso. Para ello se construían los canales o calces que permitían la entrada y salida del agua, un procedimiento habitual utilizado para los molinos harineros de la zona.

${ }^{29}$ Barceló, C. y Labarta, A., «La industria azucarera en el litoral valenciano y su léxico (siglos XV-XVI)», La caña de azúcar en el Mediterráneo... pp. 75 y 81; Martínez, M., «Producción de azúcar en Murcia...», p. 155.

${ }^{30}$ Parece que el primer ingenio de azúcar movido por agua fue patentado por Diego de Teive en 1492, vid. Vieira, A., «Agua, trabalho e açucar. O caso da Madeira nos séculos XVI e XVII», Agua, trabajo..., p. 110.

${ }^{31}$ González Tascón, I., Fernández Pérez, J., «El azúcar en el viejo mundo. El impacto de su elaboración», La caña de azúcar en tiempos de los grandes descubrimientos. 1450-1550, Motril, 1990, pp. 104-106.

${ }^{32}$ ADMS, 1041, Papeles por donde..., Sanlúcar, Cartas de pago de 16 y 8 de diciembre de 1546.

${ }^{33}$ ADMS, 2451, Cuentas de los tesoreros..., Recados de la cuenta que dio Francisco Díaz como recaudador de las rentas de Jimena en el año 1550. 
Los ingenios de azúcar contaban con varios espacios en los que se realizaban las diferentes labores. La primera zona era un lugar donde se recepcionaban las cañas ya cortadas, transportadas en haces desde la plantación, y donde se procedía a su troceado. Para esta primera fase, el utillaje industrial estaba formado por cuchillos o machetes afilados. ${ }^{34}$ En Jimena están documentadas varias hachas calzadas de hierro y acero, fabricadas por herreros, así como el pago a barberos por la «amoladura» de las mismas o por la compra de una piedra para «cymolar las herramientas».

Al igual que todos los ingenios, el de Jimena se fabricó a base de mucha madera y poco hierro, por ello, el principal artífice fue el maestro de la madera del ingenio, ayudado por otros carpinterios, unos oficiales y otros maestros que colaboraron con él en labrar la rueda. Lo hizo a lo largo de 1547, y esto le supuso vivir apartado de la villa. En el mes de agosto cayó enfermo, y como tenía necesidad de «dineros para curarse», el alcaide de Jimena mandó al recaudador que le diera 18 reales. Al mes siguiente, en septiembre, el duque dio un mandamiento para que se le entregaran, a cuenta de lo que se le debía, 6 reales para que pudiera purgarse ${ }^{35}$ En ese año, desde agosto hasta diciembre, se le hicieron varios pagos por los trabajos realizados, para su manutención y para pagar a los otros carpinteros.

Como ya se ha dicho, el material principal era la madera, pero también se necesitaba el hierro para los clavos de «chapajo» y de «tinglado», los cinchos, «alcaiatas y otras cosas». Cuando se estaba construyendo el ingenio, el duque mandó que se comprara en Cádiz parte de la clavazón y del hierro que se necesitaban y determinó que se llevaran en el primer barco que saliera para Gibraltar. Una vez allí, se debía avisar al alcaide de Jimena para que mandara a recogerlo. ${ }^{36}$

Levantado el ingenio, comenzó el proceso de producción del azúcar, el cual pudo realizarse al completo, como se ha podido comprobar en los mandamientos de pago del año 1548 y en los testimonios de gastos de $1551 .{ }^{37}$

Una vez troceadas y lavadas las cañas, se procedía a molerlas. La maquinaria para el proceso de la molienda era toda de madera. Se construyó una noria que, movida por la corriente del agua del río, conducida a través de los calces, producía la fuerza necesaria para que giraran los rodetes con dos mazas, unidos al eje con cinchos o aros de hierro. Por la presión de las dos mazas o cilindros horizontales, a través de los cuales se introducían las cañas, se realizaba una primera extracción del jugo. El encargado de ir introduciendo las cañas era el moledor, que era ayudado por otras dos personas. En la misma zona se situaban unos tableros apoyados en «tablas ginesas» para ir depositando las cañas.

\footnotetext{
${ }^{34}$ González Tascón, I. y Fernández Pérez, J., «El azúcar en el viejo mundo...», p. 106.

${ }^{35}$ ADMS, 2451, Cuentas de los tesoreros..., Recados de la cuenta que dio Francisco Díaz como recaudador de las rentas de Jimena en el año 1547, Jimena, 1547.IX.22.

${ }^{36}$ ADMS, 1041, Jimena, 1546 Papeles por donde..., Sevilla, 1547.IX.3.

37 ADMS, Leg. 2451, Cuentas de los tesoreros..., Recados de la cuenta de Francisco Díaz recaudador de Jimena del año 1548 y 1551; para el proceso vid. Malpica, A., «Arqueología y azúcar..., pp. 123-153; Lobo Cabrera, M., «Azúcar y trabajo en Canarias...», pp. 228-236; Von Wartburg, M.L., «Desing and technology of the medieval refineries of the sugar cane in Cyprus. A case of study in industrial archaeology», Paisajes del azúcar... pp. 81-116; Barceló, C. y Labarta, A., «La industria azucarera en el litoral valenciano...», pp. 78-79.
} 


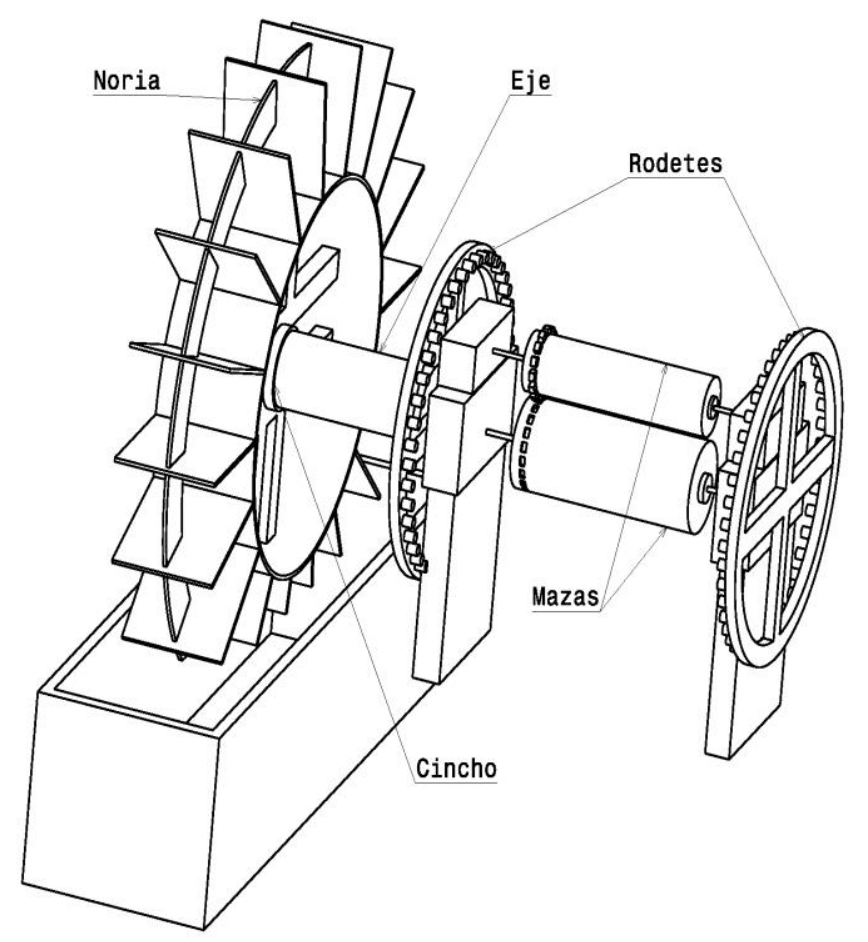

Fig. 5. Alzado de la zona de la primera molienda. (Elaborado por Ana Toribio Moreno).

Extraídas las mieles, se echaban en tinajas. De estas queda constancia en la documentación. En julio de 1548 se dio mandamiento porque «Martín Delgado Repilado vecino de Jimena prestó una tinaja hace 2 años cuando molía el trapiche para echar las mieles y como es difunto y pide la tinaja su mujer y esta tiene mieles y no se puede vaciar convinose la dicha mujer en que se le pague por ella 1 ducado». Ese año también se hizo el pago de otras dos tinajas, a un ducado cada una.

Junto a la maquinaria de la molienda se colocaba la prensa, elemento necesario para, en un segundo paso, conseguir extraer todo el jugo de la caña. No sabemos si en el ingenio de Jimena había una o más. Estaba fabricada también con madera, formada por varias grandes vigas unidas con una cuerda gruesa llamada guindaleta, la cual se clavaba a las maderas con clavos de hierro.

En un extremo de la prensa se encontraba el husillo, especie de tornillo de madera que, mediante barras laterales, se hacía girar con el fin de que la viga descendiera. Para que girara con fluidez se le aplicaba jabón y cebo. Mientras bajaba la viga se ejercía presión en la parte central o pinza, donde se colocaban, en capazos o sacos, las cañas, una vez que se les había sacado la sacarosa en el proceso de la molienda. Parece que, en Jimena, según los pagos que se realizaron, las cañas debían introducirse para el prensado en pellejos. 


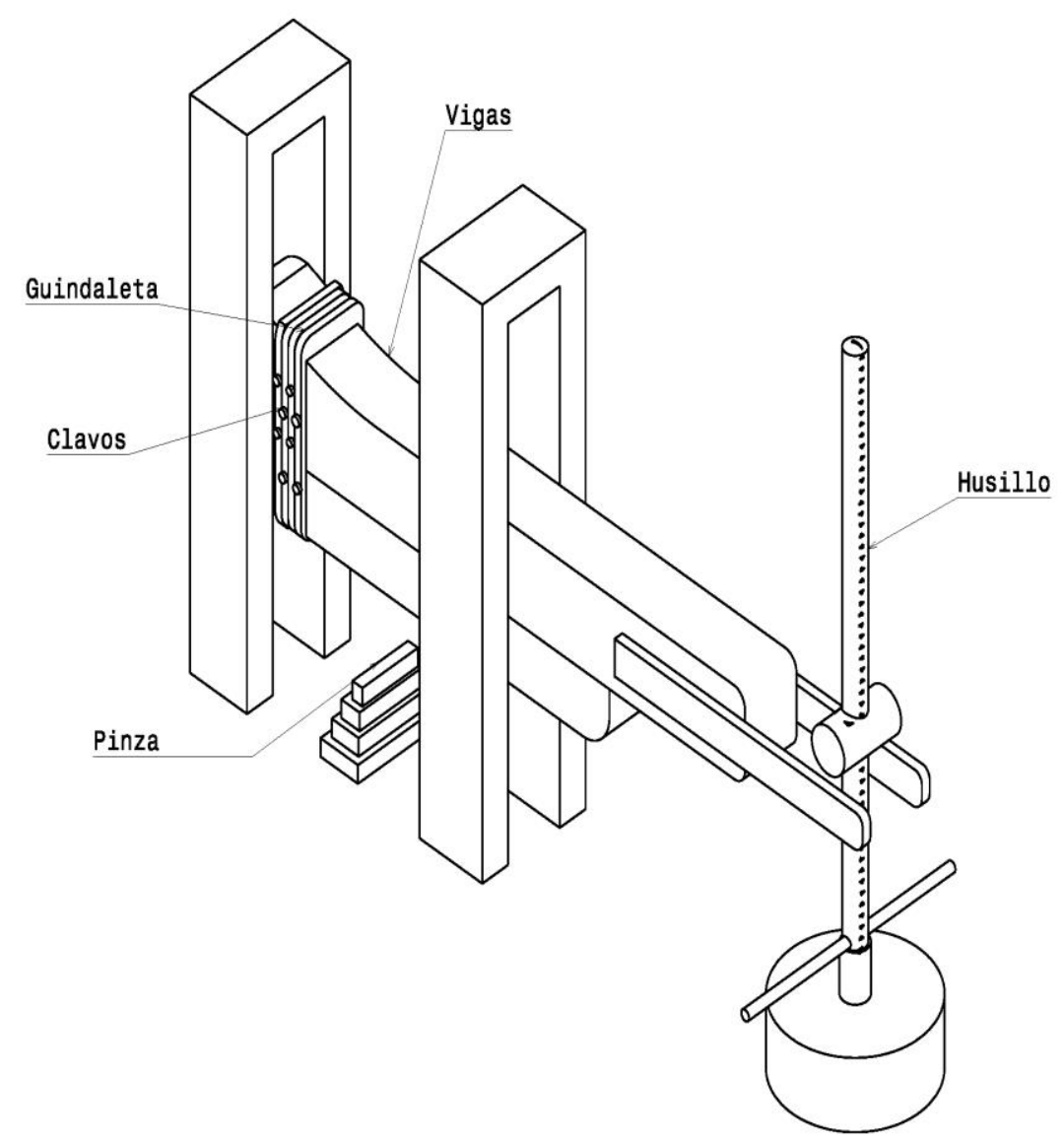

Fig. 6. Alzado de la prensa. (Elaborado por Ana Toribio Moreno).

Una vez que finalizaba la segunda trituración, el dulce jugo extraído era conducido, mediante canalizaciones, hacia una vasija grande en la zona de las calderas, situada en la cocina.

El ingenio de Jimena, como el de otros lugares, contaba, con otras dos estancias, la casa despensa y la cocina. ${ }^{38}$ Sabemos que tenían cuatro puertas ya que el carpintero Bartolomé Díaz hizo en 1547 sus umbrales. La parte de la cocina se destinaba al proceso de cocción y refinado.

Había que hervir el jugo de la caña para separar los diferentes componentes y concentrar la sacarosa. Esto implicaba la utilización de calderas de cobre que se ponían al fuego en fogones o fornallas alimentados por gran cantidad de leña. También se utilizaba como material de combustión el bagazo o restos de las cañas una vez que se habían prensado. Otro uso de estos residuos era el abono.

La cocción se realizaba solo en unas semanas del año, pero se trabajaba ininterrumpidamente y por ello se gastaba mucha leña, lo que provocaba la despoblación de algunas zonas de bosque. ${ }^{39}$ Según lo recogido en el apeo de las dehesas, en la ribera del Guadiaro, en la parte de la Vega de los Granados, había 20 álamos, algunos de ellos muy viejos, que estaban huecos y nudosos y otros desmochados y maltratados. En toda la dehesa había 130 álamos y unos 7.120

\footnotetext{
${ }^{38}$ Gisbert, J.A., «En torno a la producción...», pp. 211-265 y Malpica, A., «Medio físico y territorio...», p. 39.

${ }^{39}$ Malpica, A., «Medio físico y territorio...», pp. 11-40. A finales del siglo XVI, en las refinerías de Sevilla se sustituyó la leña por el orujo de aceituno para cocer el azúcar porque resultaba mucho más económico, Vid. Del Río, J., «Refinerías de azúcar en Sevilla (s. XVI-XVII)», La caña de azúcar en tiempos..., p. 145.
} 
alcornoques que no servían más que para la bellota y no para madera. ${ }^{40}$ No sabemos si la leña utilizada se tomó de los árboles de la Vega o de las dehesas colindantes. En cualquier caso, tampoco consta protesta de los vecinos por el perjuicio que se pudiera estar ocasionando por el uso de este recurso, que se consumía en abundancia en los meses de explotación del ingenio.

Los utensilios de cobre necesarios fueron llevados por Alfonso Paredes y compañeros, como consta en un mandamiento del duque de 1548 para darles «220 reales por 264 reales que montan el cobre que llevan en 11 bestias para el ingenio de azúcar porque los 44 reales han recibido de Fernando Bueno».

El trabajo en las calderas era más especializado y por ello el salario que se pagaba era superior. El jugo se cocía en torno a los $100^{\circ} \mathrm{C}$ de temperatura para detener la acción microbiológica. Había que vigilar que el azúcar no se pegase ni quemase, dándole vueltas con las batideras. Una vez conseguido cierto espesor en el jugo, se trasegaba a otros recipientes, también de cobre, que en Canarias se denominaban tachos. ${ }^{41}$ Era necesario repetir las cocciones hasta acabar de cocer la melaza y darle el punto de azúcar. El templador tenía la misión de templar las espumas y reespumas, aunque a veces esta tarea la desempeñaba el maestro de azúcar, como también sucedió en Jimena, cuando Diego González sirvió en el ingenio. Para ello se ayudaba de utensilios como los dos remiñoles o espumaderas para sacar la miel, que un cerrajero adobó por 4 reales.

Una vez que se concluía el trabajo en las calderas, el paso siguiente era el refinado cuyo fin era conseguir un producto fino y puro y de la mayor blancura posible. El maestro del azúcar era el encargado de refinar las mieles y remieles y purgar los azúcares. Para el refinado se solía añadir a las calderas un poco de cal con el fin de que los alcaloides neutralizaran el ácido que por su propia naturaleza contenían las cañas. La alta temperatura y el elevado $\mathrm{pH}$ servían para coagular las proteínas que eran eliminadas durante el proceso de clarificación. En otros lugares se usaban las llamadas lejías o sustancia que permitía que las impurezas subiesen con rapidez arriba y así se pudieran retirar.

Las mieles se colaban utilizando jerga, una tela de lana gruesa y tosca cuyo tejido forma rayas diagonales. En la relación de gastos de 1551, en el mes de marzo, constan 10 varas de «jerga para coladeros del azúcar», y en mayo, cinco varas «para colar las mieles que se cocieron».

Una vez finalizado el trabajo en la cocina, obtenida la melaza (mezcla purificada de cristales y jarope), se pasaba a la casa despensa, donde el producto se vertía en unos recipientes de barro, de forma cónica, con un orificio en la parte inferior, conocidos con el nombre de formas. Estas se colocaban con la parte del orificio hacia abajo, sobre porrones o vasijas de barro, que dejaban espacio libre para cuando se abría el agujero. Al enfriarse el azúcar, esta cristalizaba, pero antes había que conseguir la purga total y el refinado. Para ello se extendía sobre la base una capa de barro que actuaba como desengrasante y blanqueador. Durante doce a quince días, el agua que este contenía empezaba a desprenderse y a descender arrastrando la melaza que aún tenía el pan de azúcar y que se diluía sin dar tiempo a que se disolvieran los cristales del azúcar.

La miel restante, que no había llegado a cristalizar y que había salido por el orificio inferior de la forma, se volvía a cocer y, por destilación nuevamente, se conseguía la remiel.

La misión del purgador concluía una vez que el azúcar se sacaba de las formas. En Jimena, está constatado que, en 1551, el maestro del azúcar estuvo

${ }^{40}$ Molina, S. y Moreno, A., «Explotación de los recursos...», p. 151.

${ }^{41}$ Lobo Cabrera, M., «Azúcar y trabajo en Canarias...», p. 233. 
varios días echando barro al azúcar para purgarla y refinarla y después para «hacelles las cañas y sacallos de las formas y poner el azúcar en las pilleras».

La manera de extraer los trozos de azúcar o panes de las formas era rompiéndolas. Esto explicaría, por un lado, el gran número de estos objetos que se utilizaban en los ingenios y, por otro, la aparición de estas sobras utilizadas por los albañiles como relleno en algunas construcciones. ${ }^{42} \mathrm{Al}$ ingenio de Jimena acudió un albañil de la villa «porque fue a tasar cierta sobra al ingenio» y se le pagaron por ello 2 reales y medio. Los panes resultantes se limpiaban y se ponían a secar al sol en las llamadas en Jimena «pilleras», donde terminaban de solidificar antes de trocearlos para meterlos en las cajas. Sabemos que se utilizó un macete, seguramente para trocear los terrones de azúcar, ya que el herrero Juan Sánchez hizo una argolla para el mismo. Por último, el encajador envolvía los panes de azúcar con papel y lo amarraba con hilo para embalarlo en las cajas de madera. Así lo hizo Bartolomé Pérez, que trabajó en el ingenio a partir de noviembre de 1550 y desde el 20 de febrero hasta el 14 de marzo del año siguiente «que son 32 días» se le pagó «por encaxador», a real al día y 1 fanega de trigo al mes, 1.088 mrs. También consta que se pagaron a Antonio González, vecino de Jimena, 5 reales porque empapeló y pesó el azúcar que el duque de Medina Sidonia tenía en el ingenio. Con anterioridad, en 1548, se anotó el gasto de dos reales por dos varas de cañamazo que se tomaron de casa de Juan Martín de Jimena, a 1 real la vara, para envolver el azúcar que se cobró del diezmo del duque y se llevó a Sanlúcar. Se cerraba así todo el proceso de obtención del azúcar en el que también era necesario contar con la ayuda de animales. Las noticias sobre ellos se encuentran en las relaciones de gastos y nos informan tanto de los propios animales como de los arreos de los mismos. Para acarrear las cañas desde la plantación hasta el ingenio, se contrataron a varios vecinos que pusieron a disposición sus animales, asnos y caballos. En la relación de gastos de 1551 figuran los siguientes:

Tabla 1. Animales de carga contratados para el traslado de las cañas de azúcar. (Elaborada por la autora).

\begin{tabular}{|c|c|c|c|}
\hline Propietario & Arrendamiento & Tiempo & Pago \\
\hline Fernán Martín & Un asno para cargar caña & 10 días & $\begin{array}{c}250 \mathrm{mrs} \text { y 10 } \\
\text { celemines de cebada }\end{array}$ \\
\hline Alfonso Gil & $\begin{array}{c}\text { Un asno que dio para acarrear } \\
\text { caña }\end{array}$ & 8 días & $\begin{array}{c}200 \mathrm{mrs} \text { y } 8 \\
\text { celemines de cebada }\end{array}$ \\
\hline $\begin{array}{c}\text { Gonzalo } \\
\text { Martín } \\
\text { Gallego }\end{array}$ & $\begin{array}{c}\text { Un asno que anduvo a traer } \\
\text { caña en el ingenio }\end{array}$ & 3 días & $\begin{array}{c}75 \mathrm{mrs} \text { y 3 } \\
\text { celemines de cebada }\end{array}$ \\
\hline \begin{tabular}{c} 
Martín González \\
\cline { 2 - 4 }
\end{tabular} & $\begin{array}{c}\text { Sirvió en el ingenio con un } \\
\text { caballo y un asno y su persona }\end{array}$ & 8 días & $\begin{array}{c}1.088 \text { mrs, 6 } \\
\text { fanegas y } 8 \text { celemines de } \\
\text { cebada }\end{array}$ \\
\cline { 2 - 4 } & $\begin{array}{c}\text { Dio el caballo y el asno para } \\
\text { acarrear caña }\end{array}$ & 5 días & $\begin{array}{c}295 \text { mrs y 1 fanega } \\
\text { de cebada }\end{array}$ \\
\hline $\begin{array}{c}\text { Francisco } \\
\text { Vázquez }\end{array}$ & $\begin{array}{c}\text { Un asno que dio para acarrear } \\
\text { caña }\end{array}$ & 7 días & $\begin{array}{c}175 \text { mrs y 7 } \\
\text { celemines de cebada }\end{array}$ \\
\hline
\end{tabular}

\footnotetext{
${ }^{42}$ Amores, F. y Chisvert, N., «Sevilla y América: Interpretación del hallazgo de un grupo de formas de azúcar del siglo XVI en la Cartuja de Santa María de las Cuevas (Sevilla)», La caña de azúcar en el Mediterráneo..., pp. 163-176. Las formas cerámicas utilizadas para cuajar y purgar el azúcar fueron encontradas en las obras de restauración de la Cartuja de Sevilla como relleno de las bóvedas.
} 
En 1549, el duque informa de que el mayordomo del ingenio, Pedro Baez, llevaba «cuatro machos para servicio del ingenio». Fueron herrados una vez por real y medio y, más tarde, por 544 mrs. Otros pagos relacionados con animales se hicieron a Juan García albardero por el adobo de una albarda y a Mari Zambrana, a quien se le encargaron dos cinchas caballares para los machos, un cabestro y dos látigos de cáñamo. También consta el pago de un real por una jáquima de un macho.

Por último, por la costa que hizo un macho en casa del mesonero Martín Alfonso, le pagaron 20 mrs. y para las dos acémilas y el caballo del mayordomo desde primero de noviembre de 1550 hasta el 19 de abril del año siguiente se gastaron 52 fanegas y 11 celemines de cebada.

\section{TRABAJADORES Y SALARIOS}

El ingenio de La Palma de Motril se desarrolló gracias a disponer de mano de obra esclavizada o semiservil. En Madeira era mixta: esclavos, libertos y libres, los cuales realizaban tareas diferenciadas y se les pagaba en dinero o azúcar, y en Gran Canaria eran los esclavos y libertos los que se encargaban de cumplir bastantes cometidos, salvo los oficios de maestros, refinadores, purgadores y espumeros. ${ }^{43}$

En el caso de Jimena, los trabajadores eran todos asalariados. Se les pagaba en dinero y en especie. Aunque solo contamos con datos dispersos a través de los recados de las cuentas del recaudador de Jimena, hemos podido constatar la presencia de todos los oficios necesarios para el trabajo en un ingenio de azúcar. ${ }^{44}$ No se tiene noticia de la procedencia de todos ellos, pero la mayoría serían de Jimena aunque fue necesario recurrir a otros lugares para encontrar personas que desarrollaran las labores más cualificadas, como el maestro de azúcar que habitaba en Casares o el carpintero de Gibraltar que se encargó de reparar la prensa, o los que se ocuparon de estudiar las posibilidades del proyecto, como el maestro de ingenios de Madeira y el carpintero y el cañero que procedían de Sanlúcar.

El primer trabajo que se realizó fue la construcción de la acequia, necesaria para el riego de las cañas, que fue llevado a cabo, en 1544, por 6 hombres durante 7 días, 3 hombres a lo largo de 6 días y un hombre durante cuatro. Todos ellos cobraron por cada día de trabajo un real y medio. ${ }^{45}$

En los años sucesivos, para su mantenimiento y limpieza fue necesario realizar algunas labores. En 1551, se pagaron en Gibraltar 8 reales por esportillas que se llevaron para limpiar «el caos y acequia del ingenio» e Hidalgo albañil cobró por un «pedazo de obra» que hizo en la misma. ${ }^{46}$

Para los trabajos en la plantación nos sirve el testimonio dado en 1544 por el cañaverero Tomé Gil. La tierra fue preparada y arada durante el mes de abril por Lope Martín, vecino de Jimena, quien echó 30 «huebras» o rejas y por ello

\footnotetext{
${ }^{43}$ Malpica, A., «Arqueología y azúcar...», p. 129; Vieira, A., «Agua, trabalho e açucar...», pp. 133-134; Torres, C., «A industria do açucar nos alvores da espansão atlântica portuguesa», $L a$ caña de azúcar en el Mediterráneo..., p. 204 y Lobo Cabrera, M., «Azúcar y trabajo en Canarias...», p. 236.

44 Vieira, A., «Agua, trabalho e açucar...», p. 115.

${ }^{45}$ ADMS, 2451, Cuentas de los tesoreros..., Recados de la cuenta que dio Francisco Díaz como recaudador de las rentas de Jimena en el año 1544.

${ }^{46}$ ADMS, 2451, Cuentas de los tesoreros..., Recados de la cuenta de Francisco Díaz recaudador de Jimena del año de 1551.
} 
se le pagaron en total 80 reales, 8 por cada 3 huebras. Al acabar el mes, se pagaron dos reales diarios a un hombre, que durante tres días surcó la tierra para plantar.

Sabemos que para el arado se utilizaron cuatro bueyes, primero por el pago que se le hizo desde el 22 de octubre de 1550 hasta el 1 de enero de 1551 a Francisco Martín boyero, y segundo, porque cuando fue desmontado el ingenio, estos bueyes se trasladaron a las almadrabas del duque, y por eso Francisco Vázquez, que invirtió en ello cinco días, cobró 8 reales (272 mrs.), por la ida y la vuelta. El tiro se trasladó primero a Gibraltar y de allí se llevó a las almadrabas. Para ello se alquiló una carreta por 6 reales (204 mrs.) a Diego Sánchez regidor.

Para la plantación de las cañas, entre el día 26 de abril y el 10 de mayo, se contrataron a varios hombres a los que se les pagó un jornal diario de un real y medio: 7 hombres, 10 días; 4 hombres, 6 días; 1 hombre, 5 días y otro hombre, 7 días. Y entre el 13 de mayo, martes, y el 17, sábado, se contrataron a 9 hombres durante cinco días, con el mismo salario, para continuar plantando las cañas y abriendo las zanjas.

De los meses de junio y julio de ese año hay información semanal de los trabajos realizados. La primera semana de junio, estuvieron en el cañaveral 4 hombres durante 4 días, 1 hombre 3 días y otro 2 . A la semana siguiente, llevaron a 6 peones el lunes, martes, viernes y sábado y a partir del lunes 16 las labores se centraron en cavar las cañas dulces:

Tabla 2. Contrato de jornaleros para el cañaveral en los meses de junio y julio de 1544 .

(Elaborada por la autora).

\begin{tabular}{|c|c|c|}
\hline Semana & Jornaleros & Días \\
\hline Del 16 al 22 de junio & $\begin{array}{c}6 \text { hombres } \\
1 \text { hombre }\end{array}$ & 6 \\
\hline Del 23 al 29 de junio & 5 hombres & 5 \\
\hline \multirow{2}{*}{ Del 30 de junio al 6 de julio } & 6 hombres & 5 \\
\hline \multirow{2}{*}{ Del 7 al 13 de julio } & 6 hombres & 3 \\
\hline & 1 hombre & 4 \\
\hline Del 14 al 20 de julio & 5 hombres & 4 \\
& 8 hombres & 3 \\
\hline
\end{tabular}

En la primera semana del mes de julio, además de cavar, los mismos hombres escardaron las cañas. En todos los casos, el salario era idéntico al que se dio a los que habían plantado, un real y medio diario.

Por su parte, a la persona que se ocupaba de regar las cañas se le hacía un contrato de mayor duración y se le pagaba por meses. En 1544, Alfonso Moreno comenzó sus labores el 11 de mayo y finalizó en el mes de septiembre. Cobró al mes un ducado y medio y una fanega de trigo. Además, el 6 de agosto, durante el periodo más seco, trabajaron 4 hombres para echar agua del río para regar las cañas y se les pagó a cada uno un real y medio.

Como ya se ha señalado anteriormente, en el momento de la siega había una operación delicada que podía garantizar la simiente del próximo año. Por este trabajo que Alfonso Moreno llevó a cabo en enero de 1552 durante seis días, se 
le pagó a un real y medio diario. ${ }^{47}$ Salvo esta información, no tenemos más noticias, en los años siguientes a 1544, de pagos realizados en la plantación, pero sabemos que continuaron las labores, pues sí existen datos de pagos a herreros por los arreglos en herramientas y utensilios. Así, en junio y julio de 1548, se dio mandamiento para pagar al herrero Juan Fernández por las reparaciones y puesta a punto de las azadas y otros materiales: el 26 de junio «adobó ocho azadas cercadas de acero y suele llevar por cada una $60 \mathrm{mrs}$. y porque a estas les ha hecho tablas hasta el ojo igualase a dos reales cada una, lleva por ellas 544 mrs.» y el 2 de julio hizo una «zimbara para rozar yerva entre las cañas» a 3 reales y 100 cuñas para las azadas con que se cavan las cañas a 1 maravedí cada una. ${ }^{48}$

Por su parte, en mayo de 1551, se dio testimonio de los gastos del pago de 5.598 mrs. y medio al herrero Juan Sánchez, quien utilizó hierro del que el duque había mandado traer, del cual conservaba todavía una cantidad por valor de unos seis reales y por ello solo se le pagaron $5.398 \mathrm{mrs}$. Entre los trabajos realizados por este herrero se encontraban:

Tabla 3. Trabajos del herrero Juan Sánchez para herramientas y utensilios.

(Elaborada por la autora).

\begin{tabular}{|c|c|c|}
\hline Material & Precio & Pago \\
\hline Un pico azadón calzado de hierro & 3,5 reales & $119 \mathrm{mrs}$ \\
\hline Una cuña adobada & medio real & $17 \mathrm{mrs}$ \\
\hline Una cuña a la que echó hierro & medio real & $17 \mathrm{mrs}$ \\
\hline Una cuña nueva & 3 reales & $102 \mathrm{mrs}$ \\
\hline 2 rejas calzadas & 2,5 reales & $85 \mathrm{mrs}$ \\
\hline Un pico que adobó & 1 real & $34 \mathrm{mrs}$ \\
\hline 4 azadas con tablas & 2 ducados & $750 \mathrm{mrs}$ \\
\hline 6 cuñas de hierro del duque & 4 reales & $136 \mathrm{mrs}$ \\
\hline 3 cuñas grandes de hierro del duque & -- & $100 \mathrm{mrs}$ \\
\hline 2 rejas calzadas & 2,5 reales & $85 \mathrm{mrs}$ \\
\hline Otras 6 cuñas del hierro del duque & 4 reales & $136 \mathrm{mrs}$ \\
\hline
\end{tabular}

Dentro de las tareas que se realizaban en el ingenio, podemos distinguir diferentes tipos de pagos según las labores más o menos especializadas que se llevaron a cabo. En primer lugar, se encuentran los que se encargaron de los trabajos auxiliares como la fabricación de la maquinaria o la construcción de sus dependencias, después los que se ocuparon de su mantenimiento y reparación, $\mathrm{y}$, por último, las personas que realizaron las diferentes labores hasta llegar a la

\footnotetext{
${ }^{47}$ ADMS, Leg. 2451, Cuentas de los tesoreros..., Recados de la cuenta de Francisco Díaz recaudador de Jimena del año 1551, Jimena, 1552.I.31.

${ }^{48}$ ADMS, Leg. 2451, Cuentas de los tesoreros..., Recados de la cuenta de Francisco Díaz recaudador de Jimena del año 1548, Jimena, 1548.VII.10.
} 
obtención del azúcar: molienda, prensado, cocción, refinado, extracción de los panes de azúcar y embalaje.

El primer paso fue la edificación del ingenio. Ya se ha señalado que el principal material utilizado fue la madera y por ello, los principales pagos se hicieron a carpinteros. A Bartolomé Díaz, por el estudio previo que hizo se le pagaron 5 ducados, lo mismo que cobró por el mismo trabajo y el camino desde Sanlúcar, el carpintero Alfonso Muñoz, a quien le acompañó el cañero Juan Hernández. A este último se le pagaron 8 ducados por el desplazamiento y el estudio de los caños de agua.

El elegido fue Bartolomé Díaz y en diciembre de 1546 se le entregaron $6.000 \mathrm{mrs}$. para la realización del mismo. Desde agosto hasta diciembre del siguiente año, se le hicieron varios pagos para su manutención, por los trabajos realizados, y para pagar a los otros carpinteros que le ayudaron, entre otros, los maestros que colaboraron con él en la fabricación de la rueda. Todo sumó un total de más de $16.000 \mathrm{mrs}$.

En los años sucesivos, en las relaciones de pago, aparecen carpinteros que realizaron labores de mantenimiento y reparación. En 1551, Francisco Martín estuvo nueve días «adobando el ingenio para moler», por lo que cobró 3 reales y medio diarios. Durante cuatro días fue ayudado por Juan García a quien se le pagaron 3 reales al día. Aparecen otros pagos a los mismos, pero no se especifican los trabajos que realizaron.

Los herreros aportaban hierro para las piezas estropeadas, herraban animales y nutrían y reparaban las calderas. En julio de 1548, se dio un mandamiento al recaudador de la villa para que pagara a Juan Fernández, herrero, $592 \mathrm{mrs}$. de las cosas que hizo en el ingenio, quien, además, el 8 de junio, viernes, llevó 300 clavos de tinglados y el día 18, 7 libras de clavos de chapajo a 17 la libra. Ese mismo día Geronimillo llevó 25 clavos para clavar la guindaleta de la prensa, a 1 maravedí cada clavo. También se pagaron, en septiembre de ese año, 3 ducados a un herrero de Jimena que fue al ingenio a hacer «alcaiatas y otras cosas» durante seis días y medio con otros tres hombres que fueron a ayudar, y $992 \mathrm{mrs}$. por clavazón, azadas y otras cosas de hierro.

Los albañiles se encargaban de la edificación y mantenimiento de las casas y de las fornallas. En 1551, se dio testimonio de que Álvaro Sánchez, albañil, labró 7 días en el ingenio adobando las fornallas por 714 mrs., e Hidalgo albañil ayudó a ello durante 5 días. También cobraron por otras tareas que no se concretan en la relación de pagos.

Ya en el proceso de elaboración del azúcar, no siempre se especifica el salario mensual del trabajo desarrollado en las distintas labores del proceso, pero para algunos coincide en 18 reales $(612 \mathrm{mrs}$.) y 1 fanega de trigo a finales de 1550 y 24 o 25 reales en los primeros meses del año siguiente, mientras se estaba realizando el prensado.

Cuando se ocupaban de tareas más específicas cobraban más y de manera diferente según el puesto que desempeñaban. Esto lo hemos podido comprobar en el caso de Andrés Martínez que sirvió en el ingenio por 2 ducados al mes y como moledor cobraba 2 ducados y medio, o Benítez, que colaboró como prensero viendo incrementado su salario en unos $30 \mathrm{mrs}$. Otro caso es el de Jerónimo Gómez quien cuando empezó a trabajar en las calderas, su salario mensual pasó de 18 reales a 3 ducados ( 1.125 mrs.) o Bartolomé Pérez que cobró durante 32 días un real diario por encajador.

A algunos se les contrataba para que se encargaran de una función concreta. Es el caso de Antonio González, calderero, quien sirvió en las calderas y además 
se le pagaron 8 reales por las «espumas que hizo» y Diego González, maestro de hacer azúcares, quien, en 1550, «del tiempo que ha servido en el ingenio» (siete meses menos cuatro días), cobró un total de $26.952 \mathrm{mrs}$., por ocuparse de templar y purgar el azúcar, refinar y cocer o hacer mieles y por su manutención (30 mrs. de ración al día). Al año siguiente, se le pagaron «por mes y medio desde 12 de febrero hasta 26 de marzo a 9 ducados de salario al mes y 30 mrs. de ración al día como con él se concertó», 6.412,5 mrs.

\section{EL FINAL DE LA EMPRESA}

En 1548, el ingenio estaba a pleno rendimiento. En los meses del verano hay constancia de lo que se llevó para la alimentación de los que trabajaban en la molienda y en el refinado. Se compró vino a Juan de Hurea, en concreto 16 arrobas de las que 3 se especifica que eran para los refinadores, a 2 reales y 1 cuartillo cada arroba. Además, se pagó un ducado a Diego Díaz alguacil, por una bota para «llevar el vino al ingenio para la gente de la molienda».

También se compraron dos fanegas de habas, a 6 reales cada una, «para que comiera la gente del ingenio». La dieta se completaba con carne que aprovisionó el carnicero Juan Fernández Vello. A este se le pagaron 160 mrs. por «la carne para la gente que molía» y $50 \mathrm{mrs}$. por 8 libras de «carne que llevaron al ingenio para los refinadores». En otra anotación aparecen «36 mrs. en carne para la gente del ingenio». Por último, queda reflejado un mandamiento de pago porque «en sábado, a 16 de junio no tenían qué comer los que muelen en el ingenio y Lucas Martín dio 10 libras de hígado con que comieron ese día». Por ello se pagaron $60 \mathrm{mrs}$.

Fueron las condiciones meteorológicas, concretamente las heladas, las que arruinaron la empresa. El 25 de enero de 1549, el duque escribe al recaudador de Jimena para que siga sus indicaciones sobre lo que había que hacer con las cañas que habían sido dañadas por el hielo. El mayordomo del ingenio en ese momento era Pedro Baes, quien proponía que se molieran algunas a mediados de marzo y se estimara si se podían hacer rimieles o panebro, y si salía bien, que se molieran más, dejando las necesarias para la siembra. La situación no era fácil pues los dueños de las tierras pedían un alto precio por ellas y había que negociar un arrendamiento por 4 o 6 años. ${ }^{49}$

En 1550, el mayordomo informa al duque de que debe acordarse con un maestro de azúcar que está en Casares para moler las cañas. El duque lo autoriza solicitando que se le avise del coste de este proceso y del provecho que se pudiera sacar de las cañas para que él valorara y estimara lo conveniente.

Al mayordomo se le habían asignado para cada año, para su acostamiento y salario, 50 ducados de oro (18.750 mrs.), más un real diario para su ración. También contaba con cuatro machos para el servicio del ingenio. Por su parte, como ya se ha indicado, el maestro de hacer azúcares cobró 26.952 mrs. por templar y purgar el azúcar, refinar y cocer o hacer mieles.

Después de un año de trabajo, en agosto de 1551, el duque decide cerrar el ingenio y rescinde el contrato a Pedro Baes quien debía entregar todas las herramientas y mieles que allí había. Las acémilas y el caballo se llevaron a Sanlúcar. A Ginés García se le pagaron 4 reales por dos días «que se ocupó en ir con las acémilas que se llevaron cargadas a Sanlúcar hasta sacarlas a Alcalá y por la vuelta», y a Francisco el negro 2 reales porque «fue a llevar las acémilas

${ }^{49}$ ADMS, 2510, Libro Manual de cuentas del duque mi señor. Año 1549, Carta para moler las cañas que se helaron. Sanlúcar, 1549.I.25, fol. 23v. 
a Sanlúcar para el gasto que se hicieron en las cargas». Por último, se adobó la silla que había traído el mayordomo en el caballo, antes de llevarlo a Sanlúcar y por este trabajo, que hizo un maestro de adobar sillas, se pagaron 6 reales, 204 mrs.

En enero de 1552, se segaron las cañas con el fin de poder aprovechar las simientes y el 9 de marzo, Francisco Díaz, el recaudador de Jimena, recibió todo y elaboró un inventario, aunque este documento desconocemos si se ha conservado. Sí contamos con los testimonios del recaudador de lo que se había gastado en el ingenio, estando presente el escribano Francisco de Molina, para quien el duque de Medina Sidonia mandó al licenciado Hernando Riquel que se le hiciera merced de esperar por el tercio de la escribanía, que se cumplía por San Juan, hasta el siguiente de San Miguel, y que se le pagara lo merecido por haberse ocupado de hacer testimonios y escrituras relacionadas con el ingenio. ${ }^{50}$ Antes del cierre, algunos vecinos de Jimena empapelaron y pesaron el azúcar y se hicieron costales y talegas para transportarla.

La empresa fue del todo ruinosa. Las inversiones fueron superiores a los beneficios obtenidos. En los testimonios de 1572, los vecinos de Jimena relatan el fracaso: «en dos años acudió muy bien y después otros dos años arrió sobre todo y no se cogió nada y así cesó la granjería de la dicha azúcar».

El duque determinó que enviaría a por las herramientas mientras que para las mieles pidió al recaudador que procurara venderlas como más se pudieran aprovechar. Para el cuidado de la casa y todo lo que contenía solicitó que se contratara a un hombre a la menor costa. También pidió que se aprovechara la semilla del cáñamo.

El 31 de enero de 1552, Salvador Martín declaró lo que se le debía por el tiempo que sirvió en guardar el ingenio y todo lo que contenía, sumando un total de 99.643 mrs., 106 fanegas y 3 celemines y medio de trigo y 57 fanegas y 6 celemines de cebada. ${ }^{51}$ Existe un testimonio de 27 de julio de ese año, en el que declara que había estado guardando la casa del ingenio cinco meses, desde primero de marzo hasta fin de julio, y que se le pagaba a razón de 15 reales y 1 fanega de trigo al mes.

Fue el final de una arriesgada aventura, que pone de manifiesto el espíritu emprendedor del duque de Medina Sidonia, señor de un gran estado. En este caso, al menos llegó a verlo en funcionamiento, cosa que no sucedió en otros lugares, como en la ciudad de Murcia, cuando un siglo atrás, en 1547, dos jurados y un vecino se asociaron para instalar un trapiche o molino azucarero, que no pudo llegar a instalarse porque cuatro años más tarde, el concejo revocó la concesión del terreno con el argumento de que el solar se necesitaba para el uso común de los vecinos y moradores de la ciudad. ${ }^{52}$

\section{CONCLUSIONES}

El cultivo y transformación de la caña constituían un negocio importante a la vez que suponían la creación de puestos de trabajo. ${ }^{53}$ El azúcar era en el siglo

\footnotetext{
${ }^{50}$ ADMS, 2451, Cuentas de los tesoreros..., Recados de la cuenta que dio Francisco Díaz como recaudador de las rentas de Jimena en el año 1550, Sanlúcar, 1551.VI.23.

${ }^{51}$ ADMS, 2451, Cuentas de los tesoreros..., Recados de la cuenta que dio Francisco Díaz como recaudador de las rentas de Jimena en el año 1551, Jimena 1552.I.31.

${ }^{52}$ Martínez, M., «Producción de azúcar en Murcia...», p. 154.

${ }^{53}$ Martínez, M., «Producción de azúcar en Murcia...», pp. 147-152. El concejo murciano intentó desde principios del siglo XV tomar iniciativas económicas que consiguieran aminorar la gran
} 
XV una mercancía de lujo que fue ocupando un lugar prioritario entre los productos que demandaba la urbanizada sociedad europea, cuyos grupos económicamente privilegiados (aristocracia y burguesía) la incorporaron a los nuevos modelos alimentarios que consolidaban su posición y diferenciación.

El azúcar de Jimena podía aportar al ducado de Medina Sidonia una nueva fuente de ingresos a través de la venta del producto. El azúcar hispánico y el italiano, y posteriormente el atlántico, se encontraban dentro de los circuitos del comercio internacional y se distribuían hasta los más lejanos mercados europeos. Además, esta producción suponía el cobro de impuestos y se podía abastecer al propio estado.

La plantación de cañas y la instalación del ingenio para la obtención de azúcar en Jimena de la Frontera se enmarcan dentro de las distintas actividades emprendedoras que inició el VI duque, D. Juan Alonso de Guzmán y Zúñiga. Además del azúcar, intentó introducir el pastel, la seda y la alfalfa, aunque con ninguno tuvo éxito. La de Jimena fue, sin duda, una empresa arriesgada, pues había que contar con las incertidumbres meteorológicas para poder darle continuidad y fueron estas las que determinaron la falta de rentabilidad con el consiguiente abandono de la plantación y el cierre de las instalaciones.

Finalmente, como su vida fue tan breve, no dio tiempo a que tuviera efectos colaterales sobre el paisaje y los recursos, como la desforestación, la reducción del policultivo o la disminución del agua para el riego de otros cultivos como pudo ocurrir en otros lugares como el levante granadino.

Los vecinos de la villa nunca se manifestaron en contra pues a través de los trabajos directos o indirectos, muchos de sus habitantes pudieron beneficiarse.

\section{BIBLIOGRAFÍA}

Álvarez de Toledo, Luisa Isabel (1984), Alonso Pérez de Guzmán, General de la Invencible, t. 1, Cádiz.

Amores CARREDANO, Fernando y CHISVERT JimÉNEZ, Nieves (1991), «Sevilla y América: Interpretación del hallazgo de un grupo de formas de azúcar del siglo XVI en la Cartuja de Santa María de las Cuevas (Sevilla)», La caña de azúcar en el Mediterráneo, Actas del II seminario Internacional, Granada, pp. 163-176.

BARCELÓ, Carmen y LABARTA, Ana (1991), «La industria azucarera en el litoral valenciano y su léxico (siglos XV-XVI)», La caña de azúcar en el Mediterráneo, Actas del II seminario Internacional, Granada, pp. 74-94.

BRESC, Henri (1991), «La canne a sucre dans la Sicilia medievale», La caña de azúcar en el Mediterráneo, Actas del II seminario Internacional, Granada, pp. 43-48.

Del Río Moreno, Justo (1990), «Refinerías de azúcar en Sevilla (s. XVIXVII)», La caña de azúcar en tiempos de los grandes descubrimientos. 1450-1550, Motril, pp. 131-155.

Domínguez OrTIZ, Antonio (1996), «Aspectos sociales del cultivo y consumo del azúcar en España», Discurso de Clausura del sexto Seminario Internacional, Agua, trabajo y azúcar, Actas del sexto Seminario Internacional, Granada, pp. 327-337.

dependencia del exterior que tenía el territorio murciano. En el caso del azúcar dependían de los judíos y genoveses o de sus agentes y por ello debían pagar unos precios muy elevados. 
GARCÍA SÁNCHEZ, Expiración (1995), «Caña de azúcar y cultivos asociados en Al-Andalus», Paisajes del azúcar, Granada, pp. 41-68.

GisBert SANTONJA, Josep Antoni (1991), «En torno a la producción y elaboración de azúcar en las comarcas de la Safor -Valencia- y la Mariana Alata-Alicante. Siglos XIV-XIX. Arquitectura y la evidencia arqueológica», La caña de azúcar en el Mediterráneo, Actas del II seminario Internacional, Granada, pp. 211-265.

GonZÁlez TASCÓn, Ignacio y FERnÁndez PÉREZ, Joaquín (1990), «El azúcar en el viejo mundo. El impacto de su elaboración», La caña de azúcar en tiempos de los grandes descubrimientos. 1450-1550, Motril, pp. 104-106.

LADERO QUESADA, Miguel Ángel (1998), «Sector agrario y ordenanzas locales: el ejemplo del ducado de Medina Sidonia y el condado de Niebla», Los señores de Andalucía. Investigaciones sobre nobles y señoríos en los siglos XIII a XV, Universidad de Cádiz, Cádiz, 1998, pp. 255-272.

Lobo CABrera, Manuel (1996), «Azúcar y trabajo en Canarias», Agua, trabajo y azúcar, Actas del sexto Seminario Internacional, Granada, pp. 223-238.

MARTíneZ MARTíNeZ, María (1994), «Producción de azúcar en Murcia: un proyecto fracasado del siglo XV», 1492: Lo dulce a la conquista de Europa, Granada, pp. 141-162.

MalpiCA Cuello, Antonio (1991), «Arqueología y azúcar, estudio de un conjunto preindustrial azucarero en el Reino de Granada: La Palma (Motril)», La caña de azúcar en el Mediterráneo, Actas del II seminario Internacional, Granada, pp. 123-153.

MalPiCA Cuello, Antonio (1995), «Medio físico y territorio: el ejemplo de la caña de azúcar a finales de la Edad Media», Paisajes del azúcar, Granada, pp. 11-40.

Molina Zújar, Salomé y Moreno Moreno, Ana (2003), «Poblamiento y ocupación del territorio en una villa de frontera: Jimena» Actas del III Congreso de Historia de Andalucía, Andalucía medieval, t. 1, Córdoba, pp. 107-119.

Molina Zújar, Salomé y Moreno Moreno, Ana (2006), «Explotación de los recursos en el entorno natural de Jimena de la Frontera tras la conquista cristiana a finales de la Edad Media», Revista Meridies, 8, pp. 141-154.

ROSENBERGER, Bernard (1996), «La production de sucre au Maroc au XVIe siecle. Aspects techniques et sociaux», Agua, trabajo y azúcar, Actas del sexto Seminario Internacional, Granada, pp. 147-180.

TORRES, Cláudio (1991), «A industria do açucar nos alvores da espansão atlântica portuguesa», La caña de azúcar en el Mediterráneo, Actas del II seminario Internacional, Granada, pp. 183-206.

VIEIRA, Alberto (1996), «Agua, trabalho e açucar. O caso da Madeira nos séculos XVI e XVII», Agua, trabajo y azúcar, Actas del sexto Seminario Internacional, Granada, pp. 101-146.

VON WARTBURG, Marie Louise (1995), «Desing and technology of the medieval refineries of the sugar cane in Cyprus. A case of study in industrial archaeology», Paisajes del azúcar, Granada, pp. 81-116.

WATSON, Andrew (1991), «Innovaciones agrícolas en el mundo islámico», La caña de azúcar en el Mediterráneo, Actas del II seminario Internacional, Granada, pp. 7-22. 